\title{
EVALUASI TIMBULNYA GENANGAN PADA CATCHMENT AREA SISTEM PEMATUSAN GREGES YANG DILAYANI RUMAH POMPA GREGES DI RAYON GENTENG SURABAYA
}

\author{
EVALUATION ON THE CAUSES OF FLOOD IN DRAINAGE \\ SYSTEM IN THE GREGES CATCHMENT AREA WHICH IS \\ SERVED BY A GREGES PUMPING STATION AT GENTENG \\ SURABAYA
}

\author{
Januar Catur Putranto ${ }^{* 1)}$ dan Mas Agus Mardyanto ${ }^{1)}$ \\ ${ }^{1)}$ Departemen Teknik Lingkungan,Institut Teknologi Sepuluh Nopember (ITS), \\ Kompleks Kampus ITS, Sukolilo, Surabaya, 60111 \\ ${ }^{*}$ E-mail: januar.putranto12@mhs.enviro.its.ac.id
}

\begin{abstract}
Abstrak
Sistem Pematusan Kota Surabaya di Rayon Genteng yaitu sistem pematusan Greges dengan luas 1.520 ha dilayani oleh Rumah Pompa Greges terdapat saluran primer yaitu saluran Greges. Saluran Greges merupakan muara dari 17 saluran sekunder. Rumah pompa di Rayon Genteng, khususnya sistem pematusan Greges selain rumah pompa Greges yang melayani saluran Greges, terdapat 4 rumah pompa yaitu Gadukan, Morokrembangan, Dupak Bandarejo, dan Asem Jaya. Variabel penelitian di sistem pematusan Greges yaitu kapasitas pompa di rumah pompa Greges, Gadukan, Morokrembangan, Dupak Bandarejo, dan Asem Jaya, debit aliran ke saluran primer yaitu saluran Greges, dan debit aliran ke saluran sekunder. Metode yang digunakan yaitu perhitungan hidrologi dan hidrolika, perbandingan terhadap kapasitas pompa saat ini dan awal, analisa Standard Operating Procedure (SOP) pengoperasian rumah pompa Greges, Gadukan, Morokrembangan, Dupak Bandarejo, Asem Jaya, dan perhitungan biaya rencana tindak lanjut. Hasil evaluasi menunjukkan di Rayon Genteng, khususnya sistem pematusan Greges dengan Saluran Greges sebagai muara didapatkan 5 saluran sekunder yaitu Tembok Gede, Semarang, Margo Rukun, Demak Timur, dan Dupak yang tidak mampu melayani karena adanya sedimen. Faktor lainnya juga tidak adanya Standard Operating Procedure (SOP) pengoperasian pompa Greges, Gadukan, Morokrembangan, Dupak Bandarejo, dan Asem Jaya. Berdasarka data yang ada tercatat pada tanggal 16 April 2016 adanya genangan seluas 5,71 ha dengan waktu 240 menit dan tinggi $40 \mathrm{~cm}$ yang merupakan salah satu genangan terbesar Rayon Genteng yang terjadi di sistem pematusan Greges. Pengerukan sedimen dipilih sebagai rencana tindak lanjut, didapatkan biaya pengerukan dengan volume sedimen $10.697 \mathrm{~m}^{3}$ sebesar Rp. 148.076.680,00.
\end{abstract}

Kata kunci: Genangan, Rayon Genteng, Rumah Pompa Greges, Saluran Greges, Sistem Pematusan Greges.

\footnotetext{
Abstract

The drainage system used in Genteng Surabaya is Greges drainage system with an area of 1520 ha served by Greges Pumping Station and one of the primary channels in Genteng, Greges channel. Greges channel receives water from 17 secondary channels. There are several pumping stations in Genteng, particularly in Greges drainage system. In addition to Greges pumping station, which serves the Greges primary channel, there are four other pumping stations, i.e. Gadukan, Morokrembangan, Dupak Bandarejo, and Asem Jaya. The research variables in the Greges drainage system include pumping capacity in Greges, Gadukan, Morokrembangan, Dupak Bandarejo, and Asem Jaya; the flow/discharge to Greges primary channel, and the flow/discharge to secondary channels. The methods used include hydrology and hydraulics calculations, comparison of current and initial pump capacity, analysis of the Standard Operating Procedure (SOP) for pump station operation in Greges,
} 
Gadukan, Morokrembangan, Dupak Bandarejo, Asem Jaya, and follow-up plan cost calculation. The results showed that in Genteng, particularly Greges drainage system, Greges channel received water from five secondary channels, i.e. Tembok Gede, Semarang, Margo Rukun, Demak Timur, and Dupak, and it was not able to handle all of the flow coming in due to buildup of sediment. Other factors that played a role include the absence of a Standard Operating Procedure (SOP) for pump operation in Greges, Gadukan, Morokrembangan, Dupak Bandarejo, and Asem Jaya. It was recorded that a 5.71 ha area of inundation occurred on 16 April 2016 for 240 minutes at water level of $40 \mathrm{~cm}$. This was one of the largest floods ever taking place in Greges drainage system, Genteng. Sediment dredging was selected as the follow-up plan, with estimate dredging cost of 10,697 $\mathrm{m}^{3}$ of sediment at IDR 148,076,680.00.

Keywords: Greges channel, Greges pump house, Gregor drainage system Inundation, Rayon Genteng.

\section{PENDAHULUAN}

Kota Surabaya sebagai salah satu satu kota pesisir dengan kondisi topografi rendah yaitu berkisar antara 3-6 meter di atas permukaan air laut menyebabkan Kota Surabaya rentan terhadap bencana genangan (Badan Pusat Statistik, 2015). Sementara itu, faktor lain penyebab genangan di Kota Surabaya adalah perubahan tata guna lahan yang terjadi secara pesat (Badan Perencana Pembangunan Kota Surabaya, 2010). Adanya kondisi tersebut, maka sudah tidak mungkin lagi beban drainase Kota Surabaya ditambah oleh perkembangan perubahan lahan yang mengakibatkan kerentanan, sehingga sarana dan prasarana drainase ini perlu ditingkatkan seiring dengan kebutuhan kota agar terbebas dari banjir atau genangan yang menyebabkan terganggunya aktifitas penduduk (Tutuko $d k k ., 2015)$.

Salah satu program dalam mengurangi permasalahan genangan di Kota Surabaya adalah Surabaya Drainage Master Plan 2018 (SDMP 2018). Aplikasi dari program tersebut yaitu dengan melakukan pembagian rayon atau sistem drainase, rehabilitasi saluran, pengalihan arus aliran banjir ke saluran lintas, bozem, dan rumah pompa. Salah satu sistem pematusan Kota Surabaya di Rayon Genteng adalah Sistem Pematusan Greges. Menurut Dinas Bina Marga dan Pematusan, ketika musim penghujan tahun 2015 wilayah Sistem Pematusan Greges merupakan wilayah dengan genangan terluas di Kota Surabaya seluas 11,83 ha yang tersebar di 13 titik (Badan Perencanaan Pembangunan Kota Surabaya dan Dinas PU Bina Marga dan Pematusan Surabaya, 2000).

Upaya untuk mengetahui penyebab timbulnya genangan di wilayah sistem pematusan Greges adalah dilakukan analisa terhadap kapasitas saluran eksisting untuk mengetahui kemampuan melayani debit limpasan air hujan, analisa Standar Operational Procedure (SOP) pengoperasian pompa, dan rencana tindak lanjut dari hasil analisa, sehingga permasalahan genangan yang muncul pada catcment area Sistem Pematusan Greges yang dilayani Rumah Pompa Greges dapat terselesaikan.

\section{METODA}

\section{Identifikasi}

Dimaksudkan untuk mengetahui secara langsung kondisi eksisting sarana dan prasarana drainase sebagai langkah awal untuk melakukan penelitian. Data dari hasil identfikasi tersebut, dilakukan evaluasi terhadap permasalahan yang terjadi sehingga dapat dilakukan rencana tindak lanjut.

\section{Studi Literatur}

Studi literatur dilakukan untuk mendapatkan dasar teori yang berkaitan dengan penelitian, 
sehingga dapat menjadi acuan dalam melaksanakan penelitian. Literatur yang digunakan, yaitu analisa analisa hidrologi, meliputi perhitungan koefisien aliran ratarata, penentuan PUH pada saluran primer dan sekunder. Analisa hidrolika, meliputi perhitungan saluran terbuka, operasional pompa, dan literatur lain yang menunjang untuk menentukan rencana tindak lanjut yang tepat.

\section{Pengumpulan Data}

Data yang dikumpulkan dalam penelitian merupakan data primer dan data sekunder. Data primer merupakan data yang didapat langsung dari survei lapangan, meliputi pengukuran dimensi saluran, tinggi sedimen di saluran, tinggi genangan, lama genangan, luas genangan kecepatan aliran (Gambar 1) (Badan Standarisasi Nasional, 2015), pengamatan operasional pompa. Data sekunder merupakan data yang diambil dari instansi-instansi yang berkaitan, yaitu Dinas PU Bina Marga dan Pematusan Kota Surabaya dan Badan Perencanaan Pembangunan Kota Surabaya untuk data perencanaan dan pemeliharaan sarana prasarana drainase, SOP pengoperasian pompa, harga satuan kerja pokok (HSPK) dan tata ruang kota serta UPT PSAWS Buntung Peketingan Kota Surabaya untuk data curah hujan harian.

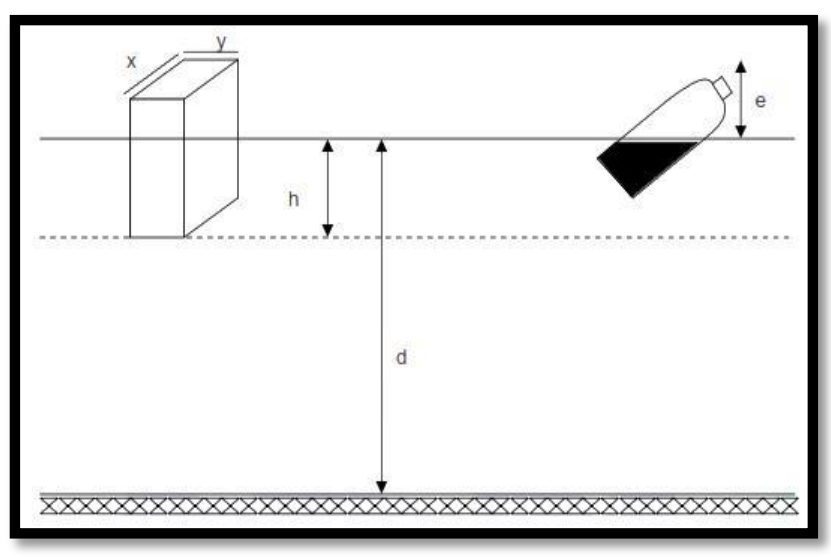

Gambar 1. Alat Ukur Kecepatan Dengan Pelampung
Keterangan:

$\mathrm{d}=$ kedalaman air $(\mathrm{m})$

a. = kedalaman pelampung $(\mathrm{m})$

$\mathrm{x}, \mathrm{y}=$ ukuran pelampung $(10-30 \mathrm{~cm})$

$\mathrm{e}=$ bagian pelampung diatas permukaan air $(5-10 \mathrm{~cm})$

\section{Pengolahan Data}

Pengolahan data dengan dilakukan analisa hidrologi untuk memperoleh debit limpasan. Dilakukan perhitungan hidrolika untuk mengetahui kapasitas saluran rencana dan kapasitas eksisting serta kemampuan kapasitas pemompaan dengan perbandingan terhadap kapasitas saat ini dan kapasitas awal, serta perhitungan biaya rencana tindak lanjut yg dipilih berdasarkan HSPK Kota Surabaya.

\section{Hasil dan Pembahasan}

Hasil dan Pembahasan dilakukan dengan melakukan evaluasi terhadap debit saluran primer Kali Greges, dan debit 17 saluran sekunder dalam melayani debit aliran hujan. analisa kapasitas pompa untuk operasional pemompaan, dan pemilihan rencana tindak lanjut yang tepat.

\section{Kesimpulan dan Saran}

Kesimpulan diperoleh berdasarkan hasil dan pembahasan yang dilakukan sehingga diperoleh masalah utama yang menjadi penyebab masih timbulnya genangan pada wilayah studi yang kemudian ditetapkannya rencana tindak lanjut yang dilakukan untuk menentukan saran untuk mengendalikan genangan yang timbul pada wilayah studi Sistem Pematusan Greges

\section{HASIL DAN PEMBAHASAN}

\section{Luas Area Sistem Pematusan Greges}

Berdasarkan kondisi topografi sistem pematusan Greges dilakukan pembagian blok pelayanan (Gambar 1) (UPT PSAWS 
Buntung Peketingan, 2015) untuk setiap segmen di saluran primer, maka diketahui luas masing-masing blok (Tabel 1)

Tabel 1. Luas Daerah Pelayanan Saluran Primer Kali Greges

\begin{tabular}{ccc}
\hline $\begin{array}{c}\text { Kode Saluran } \\
\text { Primer Kali } \\
\text { Greges }\end{array}$ & $\begin{array}{c}\text { Luas Daerah } \\
\text { (ha) }\end{array}$ & $\begin{array}{c}\text { Panjang } \\
(\mathrm{m})\end{array}$ \\
\hline A-B & 300,01 & 457 \\
B-C & 143,12 & 366 \\
C-D & 98,17 & 406 \\
D-E & 120,64 & 324 \\
E-F & 29,53 & 226 \\
F-G & 97,65 & 335 \\
G-H & 102,93 & 312 \\
H-I & 143,76 & 616 \\
I-J & 87,37 & 423 \\
J-K & 327,44 & 210 \\
K-L & 68,89 & 553 \\
Total & 1520 & 4228 \\
\hline
\end{tabular}

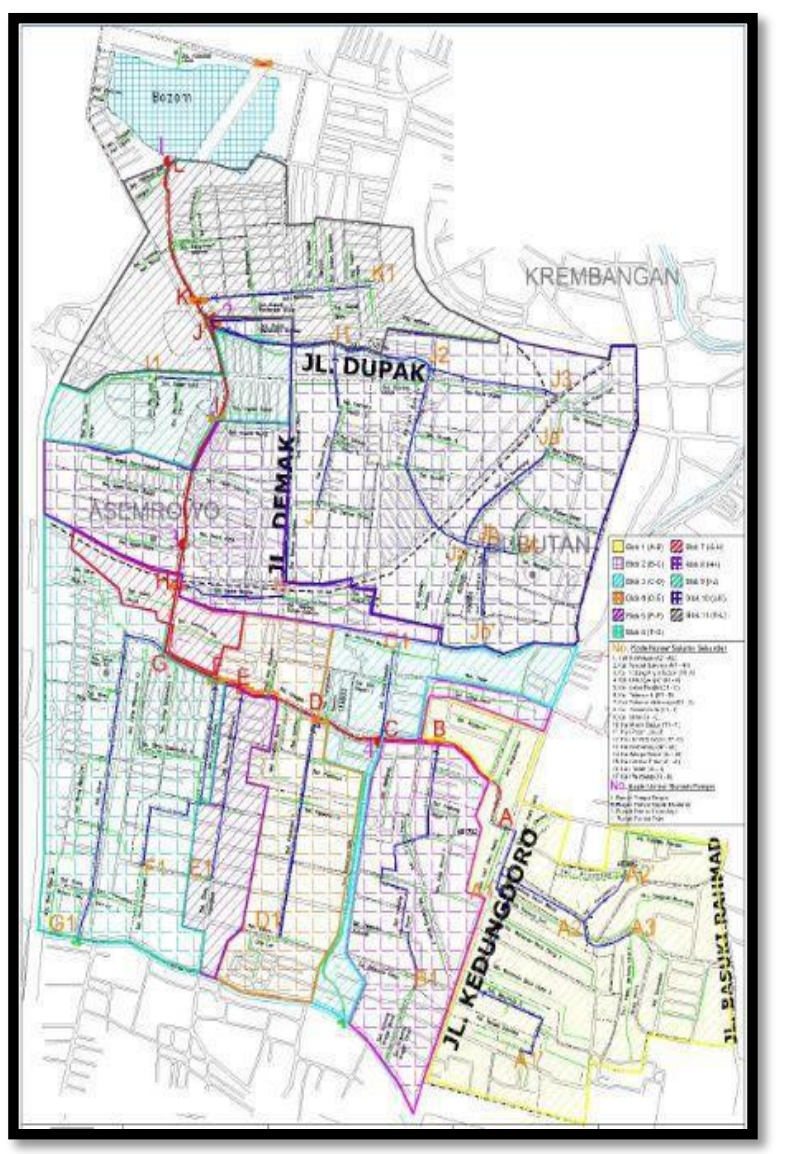

Gambar 1. Peta Sistem Pematusan Greges

\section{Perhitungan Debit Limpasan Hujan}

Penentuan besarnya debit limpasan tergantung pada besarnya intensitas hujan yang terjadi serta luas area dan fungsi tata guna lahan yang memberikan pengaruh pada nilai koefesien aliran. Dari fungsi tata guna lahan tersebut diketahui nilai koefesian aliran, sehingga didapatkan debit limpasan hujan (Tabel 2).

Tabel 2. Hasil Perhitungan Debit Limpasan Hujan

\begin{tabular}{|c|c|c|c|c|}
\hline $\begin{array}{c}\text { Saluran } \\
\text { sekunder }\end{array}$ & $\begin{array}{c}\text { A } \\
\text { limpasan } \\
\text { kuulatif } \\
\text { (ha) }\end{array}$ & $\begin{array}{l}\text { Koefisien } \\
\text { aliran } \\
\text { kumulatif }\end{array}$ & $\begin{array}{c}\text { Intensitas } \\
\text { (mm/jam) } \\
\text { PUH } 5\end{array}$ & $\underset{\left(\mathrm{m}^{3} / \mathrm{dt}\right)}{\mathrm{Q}}$ \\
\hline \multicolumn{5}{|c|}{ Kali Surabayan } \\
\hline $\mathrm{A} 2^{\prime}-\mathrm{A} 2$ & 79,19 & 0,81 & 30,83 & 0,55 \\
\hline \multicolumn{5}{|c|}{ Kali Tempel Sukorejo } \\
\hline $\mathrm{A} 11^{\prime}-\mathrm{A} 1$ & 103,23 & 0,80 & 12,84 & 0,23 \\
\hline \multicolumn{5}{|c|}{ Kali Kedung Anyar Wetan } \\
\hline A3-A2 & 45,11 & 0,79 & 34,69 & 0,30 \\
\hline A $2-A 1$ & 124,30 & 0,80 & 24,67 & 0,56 \\
\hline A1-A & 227,53 & 0,80 & 26,44 & 0,58 \\
\hline
\end{tabular}

Kali Kedung Anyar

$\begin{array}{rrrrr}\text { B1-B } & 105,91 & 0,80 & 15,17 & 0,27 \\ \text { Kali Genie Pelajar } & & & \\ \text { C1-C } & 82,95 & 0,83 & 38,94 & 0,62\end{array}$

Kali Petemon V
D1-D
90,83
0,77
16,91
0,25

Kali Petemon Sidomulyo

$\begin{array}{lllll}\text { E1-E } & 102,93 & 0,77 & 18,89 & 0,32\end{array}$

Kali Pacuan Kuda

$\begin{array}{lllll}\text { F1-F } & 75,62 & 0,76 & 12,89 & 0,21\end{array}$

Kali Simo

$\begin{array}{lllll}\text { G1-G } & 102,93 & 0,77 & 29,38 & 0,56\end{array}$

Kali Asem Bagus

$\begin{array}{ccccc}\mathrm{H} 1-\mathrm{H} & 58,73 & 0,77 & 21,82 & 0,27\end{array}$

Kali Pasar Loak

$\begin{array}{lllll}\text { I1-I } \quad 90,83 & 0,77 & 31,32 & 0,49\end{array}$

Kali Tembok Gede

\begin{tabular}{|c|c|}
\hline $\mathrm{Jb}^{\prime}-\mathrm{Jb}$ & 63,04 \\
\hline
\end{tabular}

Kali Semarang

$\begin{array}{lllll}\text { Ja'-Ja } & 44,74 & 0,76 & 18,73 & 1,39\end{array}$

Kali Margo Rukun

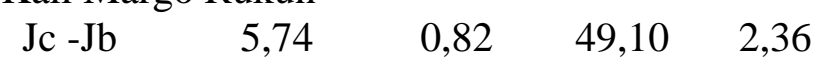




\begin{tabular}{|c|c|c|c|c|}
\hline $\begin{array}{c}\text { Saluran } \\
\text { sekunder }\end{array}$ & $\begin{array}{c}\text { A } \\
\text { limpasan } \\
\text { kuulatif } \\
\text { (ha) }\end{array}$ & $\begin{array}{l}\text { Koefisien } \\
\text { aliran } \\
\text { kumulatif }\end{array}$ & $\begin{array}{c}\text { Intensitas } \\
\text { (mm/jam) } \\
\text { PUH } 5\end{array}$ & $\underset{\substack{\mathrm{Q} \\
\left(\mathrm{m}^{3} / \mathrm{dt}\right)}}{\mathrm{l} a \mathrm{C}^{2}}$ \\
\hline $\mathrm{Jb}-\mathrm{Ja}$ & 68,78 & 0,83 & 33,63 & 2,74 \\
\hline Ja-J2 & 120,88 & 0,81 & 23,96 & 2,82 \\
\hline \multicolumn{5}{|c|}{ Kali Demak Timur } \\
\hline $\mathrm{J}-\mathrm{J} 1$ & 234,71 & 0,83 & 17,35 & 0,94 \\
\hline \multicolumn{5}{|c|}{ Kali Dupak } \\
\hline $\mathrm{J} 3-\mathrm{J} 2$ & 5,75 & 0,80 & 30,64 & 3,33 \\
\hline J2-J1 & 126,63 & 0,81 & 24,70 & 3,89 \\
\hline J1-J & 361,34 & 0,82 & 24,05 & 4,14 \\
\hline \multicolumn{5}{|c|}{ Kali Rembang } \\
\hline $\mathrm{K} 1-\mathrm{K}$ & 45,78 & 0,79 & 28,75 & 0,29 \\
\hline $\begin{array}{l}\text { Saluran } \\
\text { Primer }\end{array}$ & $\begin{array}{c}\text { A } \\
\text { limpasan } \\
\text { kuulatif } \\
\text { (ha) }\end{array}$ & $\begin{array}{l}\text { Koefisien } \\
\text { aliran } \\
\text { kumulatif }\end{array}$ & $\begin{array}{c}\text { Intensitas } \\
(\mathrm{mm} / \mathrm{jam}) \\
\text { PUH } 10\end{array}$ & $\underset{\substack{\mathrm{Q} \\
\left(\mathrm{m}^{3} / \mathrm{dt}\right)}}{\mathrm{Q} a \mathrm{C}^{2}}$ \\
\hline A-B & 266,86 & 0,80 & 27,58 & 1,56 \\
\hline $\mathrm{B}-\mathrm{C}$ & 409,98 & 0,80 & 31,02 & 2,73 \\
\hline C-D & 508,23 & 0,80 & 33,71 & 3,70 \\
\hline D-E & 628,87 & 0,79 & 33,59 & 4,56 \\
\hline E-F & 658,40 & 0,79 & 50,97 & 7,20 \\
\hline F-G & 756,05 & 0,79 & 39,23 & 8,83 \\
\hline $\mathrm{G}-\mathrm{H}$ & 858,98 & 0,79 & 39,34 & 8,87 \\
\hline H-I & 1002,8 & 0,78 & 33,66 & 9,47 \\
\hline I-J & 1090,2 & 0,78 & 38,89 & 8,95 \\
\hline $\mathrm{J}-\mathrm{K}$ & 1451,5 & 0,79 & 27,24 & 8,63 \\
\hline $\mathrm{K}-\mathrm{L}$ & 1520 & 0,78 & 39,26 & 12,2 \\
\hline
\end{tabular}

Tabel 3. Hasil Perhitungan Kapasitas Saluran

\begin{tabular}{|c|c|c|c|c|c|}
\hline \multicolumn{6}{|c|}{ Saluran sekunder } \\
\hline \multicolumn{2}{|c|}{ Luas $\left(\mathrm{m}^{2}\right)$} & \multicolumn{2}{|c|}{$\begin{array}{c}\text { Kapasitas } \\
\text { saluran }\left(\mathrm{m}^{3}\right)\end{array}$} & \multicolumn{2}{|c|}{ Debit $\left(\mathrm{m}^{3} / \mathrm{dt}\right)$} \\
\hline A & $\mathrm{B}$ & A & $\mathrm{B}$ & A & $\mathrm{B}$ \\
\hline \multicolumn{6}{|c|}{ Kali Surabayan (A2'-A2) } \\
\hline 10,55 & 9,82 & 6497 & 6052 & & 1,3 \\
\hline \multicolumn{6}{|c|}{ Kali Tempel Sukorejo (A1'-A1) } \\
\hline 15 & & 3689 & 205 & & 2,2 \\
\hline \multicolumn{6}{|c|}{ Kali Kedung Anyar Wetan (A3-A) } \\
\hline 13,92 & 13,17 & 8325 & 7879 & & 1,7 \\
\hline & & 1203 & 11. & & 1,7 \\
\hline 12,19 & 11,56 & 7097 & 6728 & & 1,9 \\
\hline \multicolumn{6}{|c|}{ Kali Kedung Anyar (B1-B) } \\
\hline 15 , & 14,20 & 4475 & T2 & & $2, \varepsilon$ \\
\hline \multicolumn{6}{|c|}{ Kali Genie Pelajar (C1-C) } \\
\hline 11,19 & 10,64 & 9066 & 8618 & & 2,6 \\
\hline \multicolumn{6}{|c|}{ Kali Petemon V (D1-D) } \\
\hline 11,28 & 10,55 & 23414 & 21910 & & 1,5 \\
\hline \multicolumn{6}{|c|}{ Kali Petemon Sidomulyo (E1-E) } \\
\hline 8,17 & 7,59 & 14291 & 13267 & & 1,1 \\
\hline \multicolumn{6}{|c|}{ Kali Pacuan Kuda (F1-F) } \\
\hline 8,76 & 8,10 & 25341 & 23423 & 1,47 & $1,($ \\
\hline \multicolumn{6}{|c|}{ Kali Simo (G1-G) } \\
\hline 43,56 &, 17 & 94221 & U592 & 38,11 & 24,1 \\
\hline
\end{tabular}

Kali Asem Bagus (H1-H)

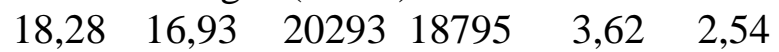

Kali Pasar Loak (I1-I)

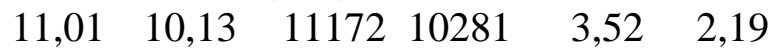

Kali Tembok Gede (Jb'Jb)

$\begin{array}{llllll}9,86 & 9,21 & 6081 & 5682 & 3,10 & 1,07\end{array}$

\section{Perhitungan Kapasitas Saluran}

Perhitungan kapasitas saluran primer Kali Greges dan 17 saluran sekunder di wilayah studi dihitung berdasarkan kondisi yang ada di lapangan yaitu dimulai saat belum terdapat sedimen (rencana) hingga kondisi saluran saat ini (eksisting) yaitu telah terdapat sedimen (Tabel 3). Pengukuran ketebalan sedimen dengan menggunakan tongkat dan kecepatan aliran dengan menggunakan metode pelampung.

Kali Semarang (Ja'-Ja)

$10,92 \quad 10,20 \quad 1323812364 \quad 1,42 \quad 1,02$

Kali Margo Rukun (Jc-Jb), (Jb-Ja), (Ja-J2)

$\begin{array}{llllll}15,01 & 13,96 & 6782 & 6310 & 3,88 & 2,33\end{array}$

$\begin{array}{llllll}14,20 & 13,27 & 6122 & 5720 & 3,16 & 2,65\end{array}$

$12,27 \quad 11,29 \quad 1872817231 \quad 3,58 \quad 2,45$

Kali Demak Timur (J'-J1)

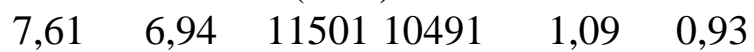

Kali Dupak (J3-J2), (J2-J1), (J1-J)

$18,24 \quad 16,56 \quad 2411121892 \quad 3,58 \quad 3,31$

$\begin{array}{lllll}17,29 & 15,71 & 1775516134 & 5,12 & 3,67\end{array}$

$\begin{array}{llllll}14,44 & 12,81 & 19524 & 17320 & 6,86 & 3,84\end{array}$

Kali Rembang (K1-K)

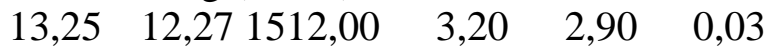




\begin{tabular}{|c|c|c|c|c|c|}
\hline \multicolumn{6}{|c|}{ Saluran primer } \\
\hline \multicolumn{2}{|c|}{ Luas $\left(\mathrm{m}^{2}\right)$} & \multicolumn{2}{|c|}{$\begin{array}{r}\text { Kapasitas } \\
\text { saluran }\left(\mathrm{m}^{3}\right) \\
\end{array}$} & \multicolumn{2}{|c|}{$\begin{array}{r}\text { Debit } \\
\left(\mathrm{m}^{3} / \mathrm{dt}\right)\end{array}$} \\
\hline $\mathrm{A}$ & B & $\mathrm{A}$ & $\mathrm{B}$ & $\mathrm{A}$ & B \\
\hline \multicolumn{6}{|l|}{$\overline{A-B}$} \\
\hline 21,19 & 16,18 & 9683 & 7395 & 10,04 & 5,93 \\
\hline \multicolumn{6}{|c|}{$\mathrm{B}-\mathrm{C}$} \\
\hline 22,45 & 16,33 & 8218 & 5976 & 9,35 & 7,62 \\
\hline \multicolumn{6}{|l|}{ C-D } \\
\hline 22,74 & 16,38 & 9232 & 6650 & 9,91 & 8,74 \\
\hline \multicolumn{6}{|l|}{ D-E } \\
\hline 23,93 & 17,19 & 7753 & 5570 & 12,55 & 10,03 \\
\hline \multicolumn{6}{|l|}{ E-F } \\
\hline 25,14 & 18,38 & 5681 & 4153 & 16,96 & 11,03 \\
\hline \multicolumn{6}{|l|}{ F-G } \\
\hline 25,63 & 17,94 & 8585 & 6010 & 21,75 & 10,76 \\
\hline \multicolumn{6}{|c|}{ G-H } \\
\hline 26,00 & 17,98 & 8112 & 5611 & 23,23 & 11,39 \\
\hline \multicolumn{6}{|c|}{ 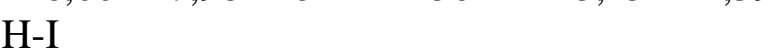 } \\
\hline 25,97 & 17,34 & 15996 & 10679 & 22,34 & 12,14 \\
\hline \multicolumn{6}{|l|}{ I-J } \\
\hline 25,96 & 16,16 & 10983 & 6835 & 23,30 & 11,85 \\
\hline \multicolumn{6}{|l|}{$\mathrm{J}-\mathrm{K}$} \\
\hline 25,72 & 16,04 & 5401 & 3368 & 24,63 & 12,03 \\
\hline \multicolumn{6}{|l|}{$\mathrm{K}-\mathrm{L}$} \\
\hline 25,25 & 15,35 & 13966 & 8486 & 24,63 & 12,03 \\
\hline
\end{tabular}

Keterangan: $\mathrm{A}=$ Rencana, $\mathrm{B}=$ Eksisting

\section{Perbandingan Kapasitas Saluran Eksisting Dengan Debit Limpasan}

Dilakukan perbandingan antara kapasitas saluran eksisting dan debit limpasan (Tabel 4) untuk mengetahui kemampuan kapasitas saluran eksisting

Tabel 4. Hasil Perbandingan Antara Kapasitas Saluran Eksisting dan Debit Limpasan

\begin{tabular}{|c|c|c|c|}
\hline \multicolumn{4}{|l|}{ 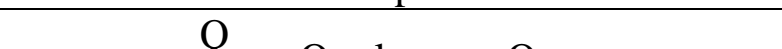 } \\
\hline Saluran & limnasa & Q saluran & \\
\hline 2 & $\mathrm{n}$ & eksisting sisa & Kesimpulan \\
\hline
\end{tabular}

Kali Surabayan

A2'-A2 $\quad 0,55 \quad 1,31 \quad 0,76 \quad$ Memenuhi

Kali Tempel Sukorejo

A1'-A1 0,23 2,22 1,99 Memenuhi

Kali Kedung Anyar Wetan

$\begin{array}{cllll}\text { A3-A2 } & 0,30 & 1,76 & 1,46 & \\ \text { A2-A1 } & 0,56 & 1,79 & 1,23 & \text { Memenuhi } \\ \text { A1-A } & 0,58 & 1,93 & 1,35 & \end{array}$

Kali Kedung Anyar

$\begin{array}{lllll}\text { B1-B } & 0,27 & 2,84 & 2,57 & \text { Memenuhi }\end{array}$

Kali Genie Pelajar

C1-C $\quad 0,62 \quad 2,66 \quad 2,04 \quad$ Memenuhi

Kali Petemon V

D1-D $\quad 0,25 \quad 1,58 \quad 1,34$ Memenuhi

Kali Petemon Sidomulyo

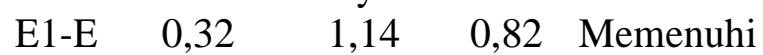

Kali Pacuan Kuda

F1-F $\quad 0,21 \quad 1,08 \quad 0,87 \quad$ Memenuhi

Kali Simo

G1-G $\quad 0,56 \quad 24,16 \quad 23,59$ Memenuhi

Kali Asem Bagus

$\begin{array}{lllll}\text { H1-H } & 0,27 & 2,54 & 2,27 & \text { Memenuhi }\end{array}$

Kali Pasar Loak

I1-I $\quad 0,49 \quad 2,19 \quad 1,70 \quad$ Memenuhi

Kali Tembok Gede

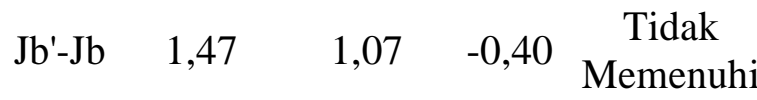

Kali Semarang

Ja'-Ja $\quad 1,39 \quad 1,02 \quad-0,37 \quad$ Tidak

Kali Margo Rukun

$\begin{array}{llllc}\text { Jc - Jb } & 2,36 & 2,33 & -0,03 & \text { Tidak } \\ \text { Jb-Ja } & 2,74 & 2,65 & -0,09 & \text { Memenuhi } \\ \text { Ja-J2 } & 2,82 & 2,45 & -0,37 & \end{array}$

Kali Demak Timur

$$
\begin{array}{llll}
\text { J'-J1 } \quad 0,94 & 0,93 \quad-0,02 & \begin{array}{c}
\text { Tidak } \\
\text { Memenuhi }
\end{array}
\end{array}
$$

Kali Dupak

$\begin{array}{ccccc}\text { J3-J2 } & 3,33 & 3,31 & -0,02 & \text { Tidak } \\ \text { J2-J1 } & 3,89 & 3,67 & -0,22 & \text { Memenuhi } \\ \text { J1-J } & 4,14 & 3,84 & -0,30 & \end{array}$

Kali Rembang

\begin{tabular}{ccccc} 
K1-K & 0,29 & 2,66 & 2,37 & Memenuhi \\
\hline & Q & Q saluran & Q
\end{tabular}

Saluran limpasa $\begin{gathered}\text { Q saluran } \\ \text { eksisting }\end{gathered}$ $1 \quad \frac{\mathrm{n}}{\mathrm{m}^{3} / \mathrm{dt} \quad \mathrm{m}^{3} / \mathrm{dt} \quad \mathrm{m}^{3} / \mathrm{dt}}$

$\begin{array}{lllll}\text { A-B } & 1,56 & 0,47 & 4,37 & \text { Memenuhi } \\ \text { B-C } & 2,73 & 0,42 & 4,89 & \text { Memenuhi } \\ \text { C-D } & 3,70 & 0,44 & 5,04 & \text { Memenuhi }\end{array}$




\begin{tabular}{ccccc} 
D-E & 4,56 & 0,52 & 5,47 & Memenuhi \\
E-F & 7,20 & 0,67 & 3,82 & Memenuhi \\
F-G & 8,83 & 0,85 & 1,93 & Memenuhi \\
G-H & 8,87 & 0,89 & 2,52 & Memenuhi \\
H-I & 9,47 & 0,86 & 2,67 & Memenuhi \\
I-J & 8,95 & 0,90 & 2,90 & Memenuhi \\
J-K & 8,63 & 0,96 & 3,40 & Memenuhi \\
K-L & 12,23 & 0,90 & 0,05 & Memenuhi \\
\hline
\end{tabular}

Keterangan: Saluran $1=$ saluran primer Saluran 2 = saluran sekunder

Diketahui bahwa kelima saluran sekunder tidak dapat melayani debit limpasan hujan. Berdasarkan hasil observasi lapangan tanggal 16 April 2016 merupakan salah satu genangan terbesar di wilayah studi, diketahui dari hasil perhitungan yaitu lama genangan maksimum yaitu 4 jam, tinggi genangan maksimum 40 $\mathrm{cm}$, dan total luas genangan 5,71 ha. Berikut adalah peta genangan Sistem Pematusan Greges seluruhnya di dalam dan luar ruang lingkup penelitian yang ditunjukkan pada Gambar 2.

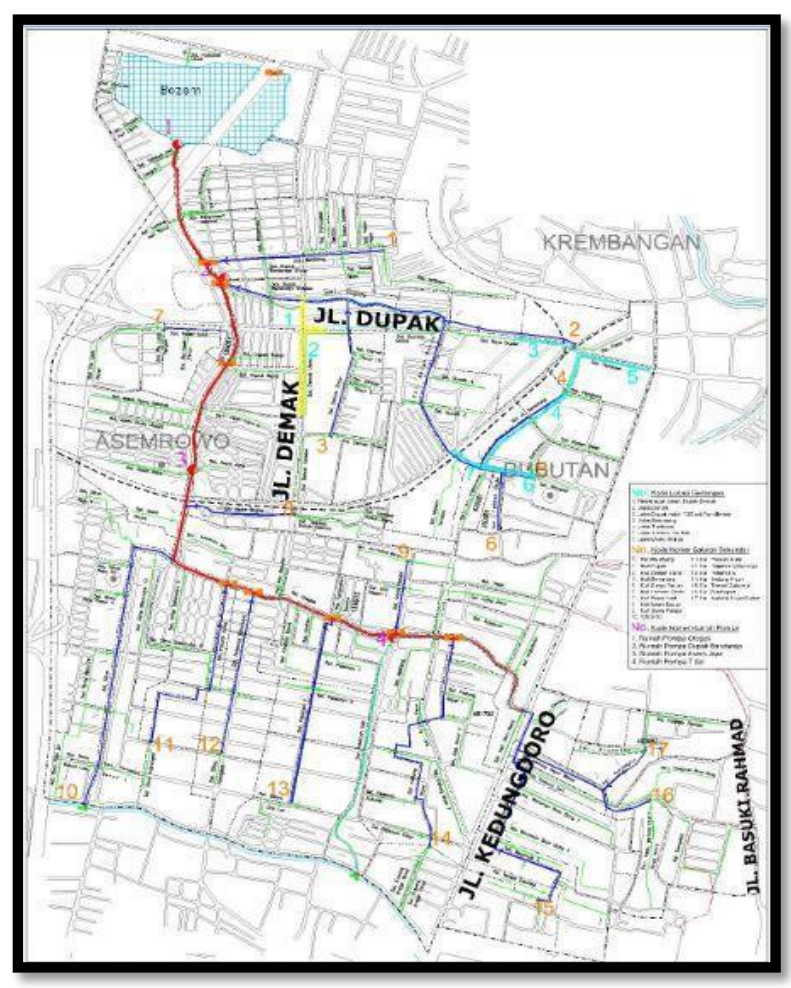

Gambar 2. Peta Genangan Sistem Pematusan Greges 2016

\section{Analisa Kapasitas Pompa Banjir}

Analisa kapasitas pompa ini dilakukan dengan membandingkan kapasitas awal pompa dengan kapasitas pompa eksisting. Kapasitas awal pompa didapat dari instansi terkait, sedangkan kapasitas pompa eksisting (Tabel 5) didapatkan dari laporan pemilaharaan yang dilakukan setiap tahunnya yang didapat dari instansi terkait.

Tabel 5. Perbandingan Kapasitas Pompa

\begin{tabular}{|c|c|c|c|c|}
\hline \multirow{3}{*}{$\begin{array}{c}\text { Nama rumah } \\
\text { pompa }\end{array}$} & \multirow{3}{*}{$\begin{array}{c}\text { Tahun } \\
\text { operasi }\end{array}$} & \multicolumn{3}{|c|}{ Total } \\
\hline & & $\begin{array}{l}\text { Jumlah } \\
\text { pompa } \\
\text { banjir }\end{array}$ & $\begin{array}{c}\text { kapasitas } \\
\text { pompa } \\
\text { banjir } \\
\text { awal }\end{array}$ & $\begin{array}{c}\text { Kapasitas } \\
\text { pompa } \\
\text { tahun } 2015\end{array}$ \\
\hline & & (Unit) & $\left(\mathrm{m}^{3}\right)$ & $\left(\mathrm{m}^{3}\right)$ \\
\hline $\begin{array}{c}\text { Dupak } \\
\text { Bandarejo }\end{array}$ & 2004 & 3 & 4,5 & 3,6 \\
\hline Greges & 2012 & 6 & 13 & 11,5 \\
\hline
\end{tabular}

\section{Analisa Pengerukan Sedimen}

Pengerukan sedimen merupakan salah satu rencana tindak lanjut yang menjadi prioritas untuk dilakukan. Berikut perhitungan yang menunjukkan bahwa apabila saluran sekunder yang tidak mampu melayani debit limpasan apabila dilakukan pengerukan kelima saluran sekunder tersebut mampu menampung limpasan hujan yang ditunjukkan pada Tabel 6.

Tabel 6. Hasil Perhitungan Pengerukkan Sedimen

\begin{tabular}{|c|c|c|c|c|c|}
\hline \multirow[t]{2}{*}{ Saluran 1} & \multirow[t]{2}{*}{ Sedimen } & $\begin{array}{c}\mathrm{Q} \\
\text { rencana }\end{array}$ & $\begin{array}{c}\mathrm{Q} \\
\text { limpasan }\end{array}$ & Q sisa & \multirow[t]{2}{*}{ Keterangan } \\
\hline & & $\mathrm{m}^{3}$ & $\mathrm{~m}^{3} / \mathrm{dt}$ & $\mathrm{m}^{3} / \mathrm{dt}$ & \\
\hline \multicolumn{6}{|c|}{ Kali Tembok Gede } \\
\hline $\mathrm{Jb}^{\prime}-\mathrm{Jb}$ & 399 & 3,1 & 1,47 & 1,63 & Memenuhi \\
\hline \multicolumn{6}{|c|}{ Kali Semarang } \\
\hline $\mathrm{Ja}^{\prime}-\mathrm{Ja}$ & 874 & 1,42 & 1,39 & 0,03 & Memenuhi \\
\hline \multicolumn{6}{|c|}{ Kali Margo Rukun } \\
\hline $\mathrm{Jc}-\mathrm{Jb}$ & 473 & 3,88 & 2,36 & 1,52 & \\
\hline $\mathrm{Jb}-\mathrm{Ja}$ & 402 & 3,16 & 2,74 & 0,42 & Memenuhi \\
\hline Ja-J2 & 1497 & 3,58 & 2,82 & 0,76 & \\
\hline
\end{tabular}




\begin{tabular}{cccccr}
\hline \multirow{2}{*}{ Saluran 1 } & Sedimen & $\begin{array}{c}\mathrm{Q} \\
\text { rencana }\end{array}$ & $\begin{array}{c}\mathrm{Q} \\
\text { limpasan }\end{array}$ & Q sisa & \\
\cline { 3 - 5 } & & $\mathrm{m}^{3}$ & $\mathrm{~m}^{3} / \mathrm{dt}$ & $\mathrm{m}^{3} / \mathrm{dt}$ & \\
\hline \multicolumn{2}{l}{ Kali Demak Timur } & & & & \\
J'-J1 & 1010 & 1,09 & 0,94 & 0,14 & Memenuhi \\
$\begin{array}{c}\text { Kali Dupak } \\
\text { J3-J2 }\end{array}$ & 2218 & 3,58 & 3,33 & 0,25 & \\
J2-J1 & 1621 & 5,12 & 3,89 & 1,23 & Memenuhi \\
J1-J & 2204 & 6,86 & 4,14 & 2,72 & \\
Total & 10697 & & & & \\
\hline Keterangan
\end{tabular}

Keterangan: Saluran 1 = saluran sekunder

\section{Analisa Standard Operating Procedure (SOP) Pengoperasian Pompa Eksisting}

Pada catchment area sistem pematusan Greges tidak ada Standard Operating Procedure (SOP) pengoperasian pompa secara tertulis. Berikut adalah rumah pompa yang melayani sistem pematusan Greges, antara lain: (Gambar 3)

1. Rumah Pompa Asem Jaya yang melayani saluran tersier Kali Asem Jaya.

2. Rumah Pompa Dupak Bandarejo yang melayani saluran sekunder Kali Dupak.

3. Rumah Pompa Greges yang melayani saluran primer Kali Greges.

4. Rumah Pompa Gadukan yang melayani Boezem Morokrembangan Selatan.

5. Rumah Pompa Morokrembangan yang melayani Boezem Morokrembangan Utara

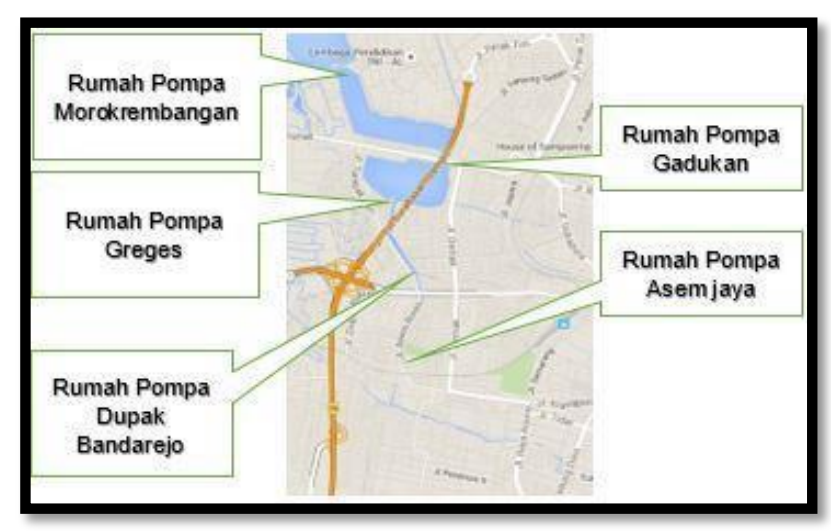

Gambar 3. Alur Pengoperasian Pompa Banjir Sistem Pematusan Greges 2016

Berdasarkan kondisi di lapangan pengoperasian pompa banjir dibedakan menjadi 3 kondisi, antara lain:
1. Kondisi sebelum terjadi laut pasang dan turunnya hujan.

2. Kondisi saat terjadi laut pasang dan turunnya hujan.

3. Kondisi setelah terjadi laut pasang dan turunnya hujan.

Meskipun telah adanya pengoperasian pompa dari segi kondisi, namun ada perbedaan pendapat dalam pengoperasian pompa yaitu Keputusan dilakukannya pengoperasian pompa banjir dengan melihat tinggi muka air di saluran, boezem, dan laut. Keputusan dalam menentukan waktu yang dibutuhkan saat pompa dioperasikan.

\section{Analisa Biaya Rencana Tindak Lanjut}

Rencana tindak lanjut dari hasil dan pembahasan yaitu dilakukan pengerukan, Diketahui pada Tabel 6 total volume sedimen pada 5 segmen saluran sekunder yaitu 10.697 $\mathrm{m}^{3}$. Pada pekerjaan pengerukan saluran digunakan metode pengerukan manual dan dengan alat berat (Tabel 7) untuk menentukan biaya yang diperlukan.

Tabel 7. Hasil Perhitungan Biaya Pengerukan

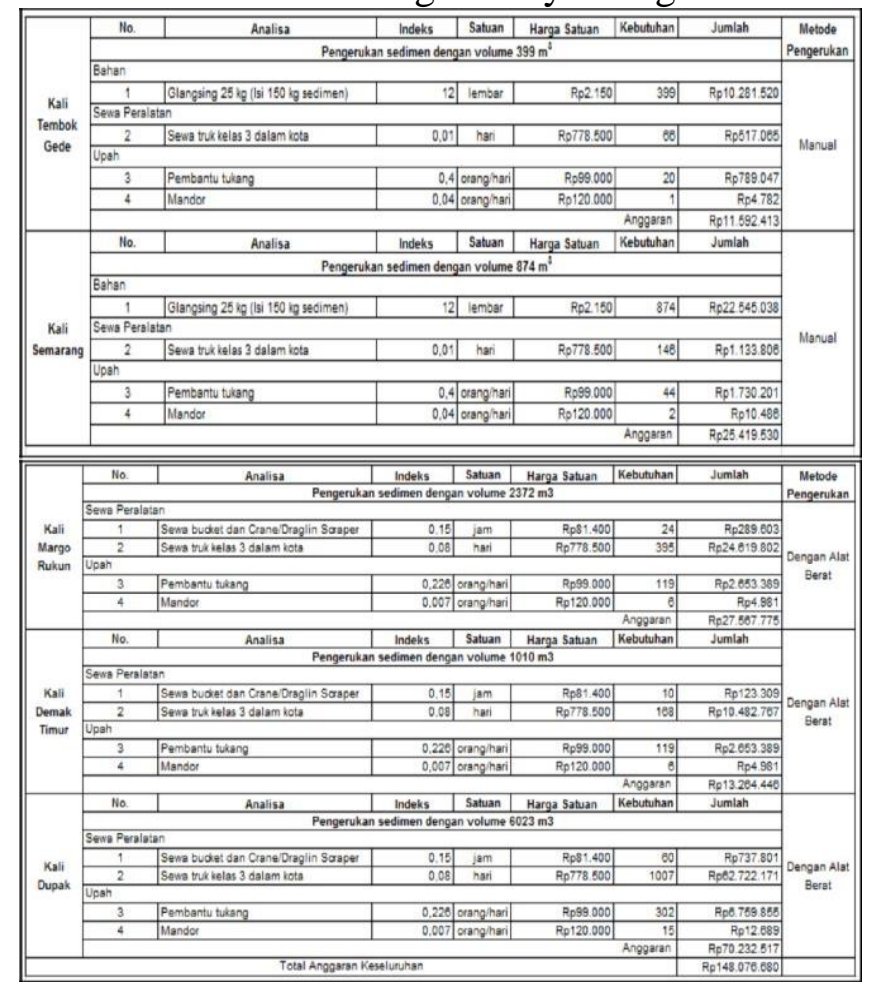




\section{KESIMPULAN}

1. Hasil dan pembahasan peyebab timbulnya genangan pada catchment area sistem pematusan Greges adalah

a. Saluran sekunder Kali Tembok Gede, Kali Semarang, Kali Margo Rukun, Kali Demak Timur, dan Kali Dupak tidak mampu menampung debit limpasan hujan, sehingga terjadi genangan dengan tinggi genangan maksimum $40 \mathrm{~cm}$, lama genangan maksimum 240 menit, dan total luas genangan 5,71 ha.

b. Saluran primer Kali Greges dengan adanya sedimen saat ini yaitu 12,28 $\mathrm{m}^{3} /$ detik, sedangkan debit limpasan hujan yaitu 12,23 $\mathrm{m}^{3} /$ detik sehingga masih mampu menampung debit limpasan hujan yang masuk ke dalam saluran primer Kali Greges.

c. Kapasitas total pompa banjir pada rumah pompa Dupak Bandarejo dalam waktu 12 tahun yang melayani saluran sekunder Kali Dupak yang merupakan muara dari 4 saluran sekunder yaitu Kali Demak Timur, Kali Margo Rukun, Kali Semarang, dan Kali Tembok Gede terjadi penurunan kinerja dari 4,5 $\mathrm{m}^{3} /$ detik menjadi 3,6 $\mathrm{m}^{3} /$ detik.

d. Kapasitas total pompa pada Rumah Pompa Greges dalam waktu 4 tahun.yang melayani saluran primer Kali Greges terjadi penurunan kinerja dari $13 \mathrm{~m}^{3} /$ detik menjadi 12,5 $\mathrm{m}^{3} /$ detik.

e. Tidak adanya Standard Operating Procedure (SOP) pengoperasian pompa di sistem pematusan Greges secara tertulis.

2. Hasil rencana tindak lanjut dan saran yang dilakukan dari hasil dan pembahasan dalam mengurangi genangan pada catchment area sistem pematusan Greges adalah a. Dilakukan pengerukan sedimen pada 5 segmen saluran sekunder yaitu Kali Tembok Gede, Kali Semarang, Kali Margo Rukun, Kali Demak Timur, dan Kali Dupak, agar saluran pada segmen tersebut dapat menampung debit limpasan air hujan yang masuk.

b. Biaya pengerukan yang diperlukan untuk 5 segmen saluran sekunder yaitu Rp. 148.076.680,00.

c. Adanya Standard Operating Procedure (SOP) pengoperasian pompa pada catchment area sistem pematusan Greges secara lisan dari hasil diskusi dengan Kepala Rayon Genteng.

d. Perlu dilakukan rehabilitasi maupun normalisasi sarana dan prasarana sistem pematusan Greges antara lain pada saluran primer, saluran sekunder, saluran tersier, rumah pompa, dan boezem morokrembangan selatan dan utara.

e. Perlu adanya pompa non permanen yang telah disiapkan untuk ditempatkan di lokasi yang rawan genangan pada catchment area Sistem Pematusan Greges untuk mengurangi genangan lebih cepat.

f. Perlu adanya Standard Operating Procedure (SOP) secara menyeluruh, meliputi normalisasi saluran dan boezem, waktu operasional dan pemeliharaan sarana dan prasarana rumah pompa, dan lain sebagainya pada catchment area Sistem Pematusan Greges.

\section{Ucapan terima kasih}

Penulis mengucapkan terima kasih kepada dosen pembimbing dan dosen penguji Tugas Akhir atas saran dan masukan terhadap penulisan jurnal dan kepada instansi-instansi yang telah memberikan perijinan dan pengambilan data serta angkatan 2012 yang 
telah memberikan semangat penulis selama masa perkuliahan.

\section{DAFTAR PUSTAKA}

Badan Standarisasi Nasional (BSN). (2015). Tata Cara Pengukuran Debit Aliran Sungai dan Saluran Terbuka Menggunakan Alat Ukur Arus dan Penampung. SNI 8066-2015. Jakarta, Indonesia

Badan Pusat Statistik Kota Surabaya. (2015). Surabaya Dalam Angka Tahun 2015. Surabaya, Indonesia

Badan Perencanaan Pembangunan Kota Surabaya. (2010). Perencanaan Pembangunan Kota Surabaya Tahun 2011-2031. Surabaya. Indonesia

Badan Perencaan Pembangunan Kota Surabaya dan Dinas PU Bina Marga dan Pematusan Surabaya. (2000). Surabaya Drainage Masterplan 2018. Surabaya, Indonesia.

Tutuko, P. dan Shen, Z. (2015). The Effect of Land Use Zonings on Housing Development:The Introduction of CDL Approach in The Border Area of Surabaya and Sidoarjo Regency, Indonesia. CITIES 2015 International Conference, Intelligent Planning Towards Smart Cities, Surabaya, Indonesia, November 3-5, 2015.

UPT PSAWS Buntung Peketingan. (2015). Data Stasiun Curah Hujan Kota Surabaya 2000-2015. Surabaya, Indonesia 